\title{
Trends and Educational Differentials in Marriage Formation Among Taiwanese Women
}

YI-CHUAN CHANG AND JUI-CHUNG ALLEN LI

\author{
WR-891
}

November 2011

This paper series made possible by the NIA funded RAND Center for the Study of Aging (P3OAG012815) and the NICHD funded RAND Population Research Center (R24HD050906).

This product is part of the RAND Labor and Population working paper series. RAND working papers are intended to share researchers' latest findings and to solicit informal peer review. They have been approved for circulation by RAND Labor and Population but have not been formally edited or peer reviewed. Unless otherwise indicated, working papers can be quoted and cited without permission of the author, provided the source is clearly referred to as a working paper. RAND's publications do not necessarily reflect the opinions of its research clients and sponsors.

RAND ${ }^{\circledR}$ is a registered trademark. 


\title{
TRENDS AND EDUCATIONAL DIFFERENTIALS IN MARRIAGE FORMATION AMONG TAIWANESE WOMEN*
}

\author{
November 1, 2011 \\ Yi-Chuan Chang \\ Department of Sociology, National Taiwan University \\ and \\ Jui-Chung Allen Li \\ Institute of European and American Studies and \\ Institute of Sociology, Academia Sinica; and \\ Population Research Center, RAND Corporation
}

\footnotetext{
*Authors are listed in alphabetical order to indicate equal contributions. Research supports come from National Institutes of Health (via seed grants as part of 5P30AG024968 and R24HD50906) and National Science Council (NSC99-2410-H-001-081). An earlier version was presented at the 2010 meeting of the Population Association of America. We thank Hyunjoon Park, Kuo-Hsien Su, Berna Torr, Yu Xie, and Chin-Chun Yi for helpful comments and suggestions. Data used in this study were collected by the Directorate-General of Budget, Accounting, and Statistics, Executive Yuan, R.O.C., and were disseminated by the Center for Survey Research, Academia Sinica. Direct correspondence to Jui-Chung Allen Li, Email: jli@sinica.edu.tw.
} 


\begin{abstract}
Using data pooled from 15 waves of the Women's Marriage, Fertility, and Employment Survey, we document trends and educational differentials in marriage formation among Taiwanese women born between 1910 and 1979. Estimates of hazard rates and cumulative probabilities of first marriage show that women born in more recent cohorts married later and less often than those born in earlier cohorts; likewise, more highly educated women tended to marry later and less often than their less educated counterparts. Educational differentials have increased across successive birth cohorts, such that one in four college-educated women born in the 1960s was never married by age 40 .
\end{abstract}




\section{Trends and Educational Differentials in Marriage Formation among Taiwanese Women}

Taiwan has one of lowest total fertility rates in the world. In 2010, an average Taiwanese woman could be expected to bear only 0.895 children by the end of her reproductive years (Republic of China Ministry of the Interior Affairs, 2011) —a rate falls far below the replacement level. As out-of-wedlock births are rare in Taiwan (the non-marital fertility ratio was below 5\% throughout the 2000s), understanding trends in marriage formation may help us understand the recent fertility decline in Taiwan.

Government statistics show that crude marriage rates in Taiwan dropped to a low point of 5.0 marriages per 1,000 people in 2009 (Republic of China Ministry of the Interior Affairs, 2010). However, crude marriage rates provide limited insight about marriage formation behaviors. Because these statistics cannot tell us whether women in Taiwan have merely delayed marriage or have forgone marriage entirely, we seek to document trends and educational differentials in the timing (when), and eventual probability (whether) of marriage formation among, Taiwanese women.

\section{THEORETICAL BACKGROUND}

\section{Theoretical Significance of Marriage Delayed versus Marriage Forgone}

The distinction between marriage delayed and marriage forgone is important because of its implications for understanding the lowest low fertility of Taiwanese women. If these women had simply delayed marriage, the current total fertility rate (henceforth, TFR) might reflect only the effects of the postponement of childbearing (Bongaarts \& Feeney, 1996) and would likely recuperate (Lesthaeghe \& Willems, 1999). However, if they forgo marriage, we would have no reason to expect the TFR to bounce back. As it is, the TFR is likely to stay low.

Our interest in studying marriage formation behaviors and our focus on the timing and 
eventual probability of marriage are also motivated by Oppenheimer's (1988) critique of the neoclassical economic model (see, Becker, 1991). While the economic model treats marriage (and non-marriage) as a pair of static statuses, Oppenheimer theorizes that marriage formation is akin to a job search process. The economic model predicts that highly educated women will be less likely to marry (as opposed to being non-married, a status which encompasses being single or separated/divorced) because they enjoy greater economic independence and realize less economic gain from marriage than their less educated counterparts. In contrast, Oppenheimer argues that it will take more highly educated women longer to search for an acceptable spouse, so they will marry at a later age; but these more highly educated women make more attractive mates, so a higher proportion of them will eventually marry compared to their less educated counterparts. In brief, from the disagreement between Oppenheimer and Becker, the lesson can be drawn that differences in when and whether to marry are distinct behavioral patterns driven by different causal mechanisms (e.g., Goldstein \& Kenney, 2001; Raymo, 2003).

\section{A Methodological Note on Marriage Delayed and Marriage Forgone}

Early research on marriage formation did not attend to the subtlety of modeling marriage delayed versus marriage forgone-these conditions were treated as two sides of the same coin (with only a handful of notable exceptions, e.g., Bloom \& Bennett, 1990). Oppenheimer and Lew (1995) made the first attempt to distinguish marriage delayed from marriage forgone in their empirical analysis. Their model allows for the effects of education to differ at different ages, and they interpreted their finding of a negative effect between education and marriage rates only at an earlier age to indicate marriage delayed. Marriage forgone, in their model, would imply a negative effect of education throughout the life course. Raymo (2003) followed the same strategy, and specified an interaction between educational attainment and 
duration since high school graduation. He then predicted the proportions of never-married women based on highly flexible parametric hazard models for up to a range of 35 to 40 years of age. The predicted proportions of never-married women clearly shows that more highly educated Japanese women born in the earlier cohort married later but not less often than their less educated counterparts born in the same cohort; by contrast, educational differentials in the more recent cohort reveals both marriage delayed and marriage forgone among Japanese women.

Goldstein and Kenney (2001) applied the Hernes model to forecast cohort trends in the proportions of ever-married women by education using data from the June 1995 Current Population Survey in the United States. Their results suggest that college-educated American women married later but not less often than their counterparts lacking a bachelor's degree. Noting that parametric forecast models often led to wildly divergent results in the proportions of never-married women because they tended to make fairly strong behavioral assumptions and to rely on data well before the respondents had reached the end of their marriageable years, Martin (2004) proposed an alternative forecasting method that provides forecasts showing converging cohort trends in educational differentials in the proportions of women never-married by age 45, using data from the 1996-2001 Surveys of Income and Program Participation.

We concur with this line of inquiry and likewise highlight that marriage delayed and marriage forgone may not be the same thing, though we recognize the possibility that marriage delayed may possibly lead to non-marriage. We also take note of the finding that different statistical forecasting models based on different behavioral and parametric assumptions may produce inconsistent results, especially during a time of rapid social change (see especially Martin, 2004). Hence, we avoid forecasts and report only estimates based on real data, as in Raymo (2003). Unlike Raymo, we do not even rely on a parametric model of 
marriage rates to predict the proportions of never-married women. Instead, we apply the semiparametric proportional hazards model (Cox 1972) to examine marriage rates; and in a separate (and thus model-independent) effort, we apply the classic nonparametric method proposed by Kaplan and Meier (1958) to estimate the proportions of never-married women.

In other words, we examine two aspects of marriage formation. We first estimate birthcohort- and education-specific eventual probabilities of marriage-defined as the proportions of women never married by a relatively advanced age. While it is difficult to define "eventual" when women continue to delay marriage so that, at least conceptually, there is always a chance that never-married women will marry at some later point, we look at the proportions of never-married women by age 30,40 , and 50 . This analysis addresses the issue of marriage forgone. We then use hazard regressions to model marriage rates-defined as the instantaneous probability of entering a first marriage at a given age for women who had never been married before this point. This analysis addresses the issue of marriage delayed.

\section{The Role of Education in Marriage Formation among Women in Taiwan}

We are interested in documenting trends in educational differentials because educational attainment serves as a proxy for economic independence in the literature. In addition, Taiwan has experienced educational expansion during the 1970s and 1980s, and we would like to understand the implications of educational expansion for marriage formation behaviors.

The modern educational system in Taiwan was established during the period of Japanese colonization. The colonial government first instituted six-year compulsory education in 1898, and enrolment rates have risen gradually ever since. Close to the end of the era of Japanese colonization, $81 \%$ of male and $61 \%$ of female Taiwanese pupils aged 6 to 12 were enrolled in school. Secondary and tertiary education systems were also established during this period, but they primarily enrolled Japanese students residing in Taiwan. Hence, the vast majority of 
Taiwanese had no more than six years of schooling in this colonial era (Tsai, 2004).

The Nationalist government took control of Taiwan after the Second World War, continued government spending in the educational system, and extended the compulsory education to nine years in 1968. The goal of educational policy during this period was to supply workers for labor intensive industries—-thus, the focus on vocational schooling. In the 1970s and 1980s, the economy of Taiwan was transformed from labor-intensive industries to high-technology industries (Hermalin, Liu, \& Freedman, 1994). In response to the increasing demand for high-skilled workers, the government relaxed regulations on tertiary education and provided much greater opportunities for tertiary education. The total number of colleges and universities jumped from 99 in 1972 to 150 in 2000 - a tremendous expansion in higher education. The deregulation and expansion of the educational system led to an upsurge in educational attainment for the Taiwanese since the 1980s (Tsai, 2004). Researchers have speculated that educational expansion, along with economic development, may be responsible for changing the marriage patterns of Taiwanese men and women (Thornton et al., 1994, Raymo \& Xie, 2000).

Using aggregate data, Casterline (1980) found that educational attainment not only had a direct effect on marriage rates, but also mediated the effect of economic development on marriage rates for Taiwanese women between 1961 and 1976. Thornton and colleagues (1994) found that changes in educational attainment fully accounted for trends in marriage rates for Taiwanese women aged 30 and younger between 1965 and 1986. They also found that other factors, such as family background, affected marriage rates through education.

Following Casterline (1980) and Thornton et al. (1994), we also examine trends and educational differentials in marriage formation among Taiwanese women in this present study. However, we use individual level data to avoid ecological inference based on aggregate data (Freedman, 2001). Our analysis of data from a series of nationally 
representative samples surveyed between 1979 and 2006 also covers a much longer period and much more recent birth cohorts than these prior studies. Moreover, unlike Thorton et al. (1994) whose sample was truncated at age 30, our sample covers women of the entire adult age range.

\section{METHOD}

Data from Women's Marriage, Fertility, and Employment Surveys

We pool data from the 1979 to 2006 waves of Women's Marriage, Fertility, and Employment Surveys (WMFES). The WMFES is a series of repeated cross-sectional surveys conducted in Taiwan that are similar to the June Supplement of the U.S. Current Population Survey (CPS). We make use of a total of 15 waves of the WMFES, conducted annually from 1979 to 1988 , and in $1990,1993,2000,2003$, and 2006. Each WMFES includes a nationally representative sample of women aged 15 and above residing in Taiwan. These surveys include information on age at the time of first marriage (measured in years), the calendar year in which a respondent was born, and the highest educational degree received. As in the June CPS, there are relatively few covariates included in the WMFES, but its large sample sizes will produce reliable estimates and thus are suitable for the descriptive purpose of this paper.

A total of 405,526 respondents were interviewed successfully in these 15 waves of the WMFES survey. We delete those respondents who were over 65 years old at the time of interview (about $8.6 \%$ ) because, especially in the older cohorts, they might be relatively advantaged in terms of socioeconomic status and health, and their marriage formation behaviors might differ from those who died before age 65 and therefore are not included in these surveys. We also delete a handful of respondents whose self-reported gender is male or whose age at first marriage occurred before they were 12 years old (because those extremely 
early marriages were likely arranged by their parents or guardians and should not be considered as voluntary marriage formation). We further restrict the analytic sample to women born before 1980 to produce reliable cohort estimates of cumulative probabilities of marriage by 30 years of age, although the unrestricted sample including women born up to 1991 gives qualitatively equivalent results as the restricted sample. These selection criteria lead to the inclusion of 351,742 cases in the analytic sample.

\section{Variables}

We are interested in modeling the event of entry into first marriage. Observations are left truncated at age 12 (leaving out only a handful of respondents) and right censored. Censoring is coded 1 if the respondent reported that she had never been married, and age at censoring for those censored is the age when she was interviewed. If the respondent reported having been married by the interview, we code an event and record her age at marriage.

We construct dummy variables to indicate the respondent's birth cohort. In the KaplanMeier analysis of cumulative probabilities of marriage formation, each cohort covers a 10year interval (except Figure 1); in the Cox models for marriage rates, each cohort covers a 20-year interval except for the most recent (1970-1979) cohort.

The respondent's educational attainment is coded into four dummy variables, according to self-reported highest grade or highest degree completed: $<12$ years of schooling (lower than high school attainment), 12 years of schooling (high-school diploma, reference category), 13-15 years of schooling (junior college degree, which includes a few types of schools conferring a degree similar to the Associate Degree in the United States), and 16+ years of schooling (bachelor's degree or higher).

\section{Statistical Models}


We use the maximum-likelihood method proposed by Kaplan and Meier (1958) to estimate cumulative probabilities of women who did not marry by age $t$ :

$$
\hat{S(t)}=\prod^{(t)}\left(1-\frac{d_{j}}{r_{j}}\right),
$$

where $r_{j}$ is the number of respondents who had never been married by age $t ; d_{j}$ is the number of respondents who entered a first marriage at age $t$. We apply this estimator to women grouped by birth cohort and educational attainment. When $t$ is some advanced age (e.g., 40 or 50) after which the age-specific marriage rates are negligible, we consider $1-\widehat{S(t)}$ as the eventual probability of ever being married for that group of women.

We estimate Cox (1972) proportional hazard models for rates of first marriage. Cox proportional hazard models assume that the differentials in marriage rates $h(t)$ are multiplicative across different birth cohorts and levels of educational attainment:

$$
h(t)=h_{0}(t) \cdot \exp \left(b_{1} \cdot \operatorname{coh}+b_{2} \cdot e d u\right)
$$

where $h_{0}(t)$ is the baseline hazard; and age, $t$, is assumed to be a continuous variable. Under the Cox model specification, we also examine whether educational differentials in marriage rates have changed across successive birth cohorts of women in Taiwan:

$$
h(t)=h_{0}(t) \cdot \exp \left(b_{1} \cdot \operatorname{coh}+b_{2} \cdot e d u+b_{3} \cdot e d u \times c o h\right) .
$$

If the coefficient for the interaction term $b_{3}$ differs significantly from zero, we conclude that educational differentials in marriage rates vary across birth cohorts.

\section{RESULTS}

\section{Descriptive Statistics}

Table 1 presents distributions of educational attainment by birth cohort for the 351,742 Taiwanese women surveyed between 1979 and 2006 and included in the analytic sample. Due to the repeated cross-sectional nature of the research design, there are more respondents 
in the middle birth cohorts, with more than half of the respondents in the analytic sample born in the 1950s and 1960s. Expansion of higher education in Taiwan did not occur until the 1980s (Tsai, 2004), and thus it is no surprise that nearly two-thirds (63\% )of the sample had less than a high school education. Comparing those women born in the 1950s and 1970s, the proportions of women with at least a high school diploma have more than doubled-with more than half of women had 12 years of schooling, $14 \%$ of women had some college education, and another 14\% of women had a bachelor's degree or higher, in the 1970-1979 birth cohort. The uneven distribution of birth cohort and educational attainment should not create any technical problem in the estimation because the sample size is large. These descriptive statistics also confirm that women born in the earlier cohorts had relatively less education than women born in more recent cohorts.

[Table 1 about here]

\section{Cohort Trends and Educational Differentials in the Probabilities of First Marriage}

In Figure 1, the Kaplan-Meier estimates of age-specific proportions of Taiwanese women who had never been married suggests a trend towards later and fewer marriages across successive birth cohorts. The proportions of women having never been married stop declining and remain constant after age 40 among those whom we had data on. In other words, very few Taiwanese women married after age 40 if they had not already done so. Thus, we use 40 years of age as the threshold to operationalize "fewer" marriages or "marriage forgone."

\section{[Figure 1 about here]}

The 5th, 10th, 15th and 20th rows in Table 2 present Kaplan-Meier estimates of the proportions of never married women by age $30,40,50$, and 60 , combining women across all levels of educational attainment. These results show that among those who were born in the 
first half of the twentieth century, fewer than $10 \%$ would never marry. In fact, most of these women were married before age 30 and many of them did so at an even younger age. This finding of an early and universal pattern of marriage based on the WMFES data is consistent with what Lin, Lee, and Thornton (1994) documented based on data from the Taiwanese census. Compared with women born in the first half of the twentieth century, women born in 1950-1959 married at a later age and more of them were never married. Still, only one in twenty women in this birth cohort were never married, indicating a high prevalence of first marriage. Women in subsequent birth cohorts continued to delay marriage, and still fewer would ever marry. The proportion of never married women by age 40 more than doubled in the next (1960-1969) birth cohort.

\section{[Table 2 about here]}

The remaining rows in Table 2 break down the Kaplan-Meier estimates of age-specific proportions of never-married women by years of schooling. The results show that trends toward later and fewer marriages are especially pronounced among highly educated women. Among women with less than a high-school education ( $<12$ years of schooling), marriage used to be, and remained, early and universal-with fewer than $10 \%$ of whom had never been married by age 30, with one exception: the 1970-79 birth cohorts. For high school graduates (12 years of schooling), there is an apparent delay in marriage formation-with more and more of these women having never been married by age 30 in more recent birth cohorts than in earlier birth cohorts. Around 10\% of high-school educated women were never married by age 40 in the 1950s and 1960s birth cohorts. Compared with earlier birth cohorts, in which only about $5 \%$ of high-school educated women were never married, this is likely to reflect not only a trend toward later marriages but also fewer marriages. We observe a similar trend towards both later and fewer marriages for women with some college education (13-15 years of schooling). The most striking finding is concerned with the proportions of women with a 
bachelor's degree or higher (16+ years of schooling) in the most recent birth cohorts: Not only did they delay marriage-with $38 \%$ of those born in the 1960 s and $56 \%$ of those born in the 1970s having never been married by age 30, but one in four of those born in the 1960s had never been married by age 40 and likely never would. The educational differentials are especially pronounced for this most recent birth cohort. Only one in twenty women with less than a high-school education was never married, compared to one in nine for high-school educated women, and one in six for women with some college education.

\section{Cohort Trends and Educational Differentials in Rates of First Marriage}

Results from Cox regression models of marriage rates in Table 3 are similar to the Kaplan-Meier estimates of the probabilities of first marriage in Table 2. Women born in recent cohorts had higher rates of a first marriage than women born in earlier cohorts; less educated women had higher rates of first marriage than more highly educated women (see Model 1, Table 3). Adding interactions of educational attainment and birth cohorts in Model 2 improves the goodness of fit (compared to Model 1, the likelihood ratio test yields $\left.\chi_{(9)}^{2}=896, p<.001 ; \Delta B I C=-783\right)$. The coefficients of these interaction terms suggest that educational differentials in marriage rates have increased across successive birth cohorts.

[Table 3 about here.]

Figure 2 graphs the relative marriage risks by education and birth cohorts, using high school graduates (12 years of schooling) born in 1910-1929 as baseline. We observe a declining trend and substantial educational differentials in marriage rates. Women of all levels of education born in the earlier cohorts were more likely to marry than their counterparts born in more recent cohorts. Less educated women in all birth cohorts were more likely to marry than their more highly educated counterparts. Figure 2 also shows that educational differentials in marriage rates have increased across birth cohorts: to illustrate, 
for example, among those women born in 1910-1929, high-school graduates were 43\% ( $\left.=\frac{100-70}{70} \times 100 \%\right)$ more likely to marry than those with a bachelor's degree or higher.

Differentials in marriage rates between high-school graduates and college graduates have increased to $47 \%$ for the $1930-1949$ birth cohort, $90 \%$ for the $1950-1969$ birth cohort, and $229 \%$ for those born in 1970-1979.

[Figure 2 about here.]

\section{DISCUSSION AND CONCLUSION}

In this paper, we document trends and educational differentials in marriage formation for successive cohorts of Taiwanese women born between 1910 and 1979. While most prior studies have treated marriage delayed and marriage forgone as two sides of the same coin, we examine both probabilities and rates of first marriage to explicitly recognize the fact that there may be an educational crossover in marriage formation (Goldstein \& Kenney, 2001; Martin, 2004). Our analysis also helps clarify the behavioral pattern responsible for the low marriage rates but hidden in official statistics, and substantially extends the study period covered in prior research (Caseterline, 1980; Thornton et al., 1994).

The results show that women with more education, or born in more recent cohorts, have been married later and less often compared with those with less education or born in earlier cohorts. Moreover, educational differentials in probabilities and rates of marriage have increased across birth cohorts. The trends and differentials we document in this paper reflect not only marriage delayed but also marriage forgone.

These findings stand in marked contrast with forecasts of trends in educational differentials in marriage formation in the United States (Goldstein \& Kenney, 2001; c.f., Martin, 2004). They also differ from findings documented in such industrialized countries as Sweden, West Germany, France, Great Britain, and the Netherlands (see various chapters in 
Blossfeld, 1995). Rather, trends and educational differentials in marriage formation among Taiwanese women seem to more closely resemble those of Japan (Raymo, 1998; 2003) and possibly Italy (Pinnelli \& de Rose, 1995). Like Blossfeld (1995) and Raymo (2003), we suspect that cultural differences in the expectation of women's role in the society may help explain the divergent findings, but an examination of such factors goes beyond the descriptive purpose of our study.

Our findings of later and fewer marriages among Taiwanese women have important implications for fertility forecasts. Because non-marital fertility is extremely rare in Taiwan, the large and increasing proportion of never married women suggests that Taiwan's low fertility rate is likely to remain low, possibly for an extended period of time. Our finding of increasing educational differentials in delayed and forgone marriage across successive birth cohorts is especially alarming as women's educational attainment continues to rise in Taiwan. The fact that one in every four college-educated women born in the 1960s having never been married by age 40 (Table 3 ) is likely to result in more than $25 \%$ of the women in that cohort remaining childless. The proportion of childless women is likely only going to become larger for those younger cohorts-more of whom are expected to receive a college education or higher, due not only to diminishing gender inequity in educational attainment but also to their relatively smaller cohort size (Easterlin, 1978). In brief, our findings suggest that, if current trends in marriage formation continue and there is no dramatic change in non-marital childbearing, it is unlikely that there will be a resurgence of fertility rates in Taiwan as in European countries (Lesthaeghe \& Willems, 1999). We believe that the government's efforts to raise the fertility rate by providing childrearing subsidies are unlikely to work unless they effectively raise marriage rates (or eliminate the normative constraints on nonmarital childbearing), and that an effective solution to the lowest low fertility will be rooted in a better understanding of the dominant trends in marriage formation: That is where the future 
research and public policy should be directed. 


\section{REFERENCES}

Becker, G. S. (1991). A Treatise on the Family. Cambridge, MA: Harvard University.

Bloom, D. E. \& Bennett, N. G. (1990). Modeling American Marriage Patterns. Journal of the American Statistical Association, 85, 1009-1017.

Blossfeld, H.-P. (Ed.). (1995). The New Role of Women: Family Formation in Modern Societies. Boulder, CO: Westview.

Bongaarts, J. \& Feeney, G. (1998). On the Quantum and Tempo of Fertility. Population and Development Review, 24 (2), 271-791.

Casterline, J. B. (1980). The determinants of rising female age at marriage : Taiwan, 1905-1976 (Doctoral dissertation). Department of Sociology, University of Michigan, Ann Arbor, MI.

Cox, D.R. (1972). Regression models and life tables (with discussion). Journal of the Royal Statistical Society. Series B (Methodological), 34 (2), 187-220.

Easterlin, R. A. (1978). What Will 1984 Be Like? Socioeconomic Implications of Recent Twists in Age Structure. Demography, 15 (4), 397-432.

Freedman, D. A. (2001). Ecological Inference and the Ecological Fallacy. International Encyclopedia for the Social and Behavioral Sciences, 6, 4027-4030.

Goldstein, J. R. \& Kenney, C. T. (2001). Marriage Delayed or Marriage Forgone? New Cohort Forecasts of First Marriage for U.S. Women. American Sociological Review, $66,506-519$.

Hermalin, A., Liu, P. K. C., \& Freedman, D. (1994). The Social and Economic Transformation of Taiwan. In A. Thornton \& H.-S. Lin (Eds.), Social Change and the Family in Taiwan (pp. 49-87). Chicago: University of Chicago. 
Kaplan, E. L. \& Meier, P. (1958). Nonparametric estimation from incomplete observations. Journal of the American Statistical Association, 53, 457-481.

Lesthaeghe, R. \& Willems, P. (1999). Is Low Fertility a Temporary Phenomenon in the European Union? Population and Development Review, 25 (2), 211-228.

Lin, H.S., Lee, M. L., \& Thornton, A. (1994). Trends in the Timing and Prevalence of Marriage. In A. Thornton \& H.-S. Lin (Eds.), Social Change and the Family in Taiwan (pp. 202-224). Chicago: University of Chicago.

Martin, S.P. (2004). Reassessing Delayed and Forgone Marriage in the United States. Russell Sage Foundation Working Paper Series: Series on Social Dimensions of Inequality. Retrieved from http://www.russellsage.org/sites/all/files/u4/Martin_Reassessing.pdf

Oppenheimer, V. K. (1988). A Theory of Marriage Timing. The American Journal of Sociology, 94, 563-591.

Oppenheimer, V. K. \& Lew, V. (1995). American Marriage Formation in the 1980s: How Important Was Women's Economic Independence? In K. O. Mason \& A.-M. Jensen (Eds.), Gender and family change in industrialized countries (pp. 105-138). New York: Oxford University.

Pinnelli, A. \& De Rose, A. (1995). Italy. In H.-P. Blossfeld (Ed.), The New Role of Women: Family Formation in Modern Societies (pp. 174-190). Boulder, CO: Westview.

Raymo, J. M. (1998). Later Marriages or Fewer? Changes in the Marital Behavior of Japanese Women. Journal of Marriage and Family, 60 (4), 1023-1034.

Raymo, J. M. (2003). Educational Attainment and the Transition to First Marriage among Japanese Women. Demography, 40, 83-103. 
Raymo, J. M., \& Xie, Y. (2000). Temporal and Regional Variation in the Strength of Educational Homogamy. American Sociological Review, 65, 773-81.

Republic of China, Ministry of the Interior Affairs. (2010). Demographic fact book, Republic of China (published annually). Taipei: Ministry of the Interior.

Republic of China, Ministry of the Interior Affairs. (2011). Demographic fact book, Republic of China (published annually). Taipei: Ministry of the Interior.

Thornton, A. \& Lin, H.-S. (Eds.). (1994). Social Change and the Family in Taiwan. Chicago, IL: University of Chicago.

Tsai, S-L. (2004). Effects of Higher Education on Inequality of Educational Opportunity. Taiwanese Sociology, 7, 47-88. 
Table 1. Distributions of Educational Attainment by Birth Cohort for Taiwanese Women $(N=351,742)$

\begin{tabular}{clcccccccc}
\hline & \multicolumn{10}{c}{ Birth cohort } \\
& & $1910-19$ & $1920-29$ & $1930-39$ & $1940-49$ & $1950-59$ & $1960-69$ & $1970-79$ & Total \\
\hline \multirow{3}{*}{ Years of } & 12 & .96 & .94 & .95 & .86 & .63 & .41 & .20 & .63 \\
Schooling & $12-15$ & .03 & .04 & .03 & .09 & .25 & .44 & .52 & .26 \\
& $16+$ & .01 & .01 & .01 & .03 & .06 & .08 & .14 & .06 \\
& $\boldsymbol{N}$ & .01 & .01 & .02 & .06 & .07 & .14 & .05 \\
\hline
\end{tabular}

Source: Women's Marriage, Fertility and Employment Surveys: 1979 - 2006. 
Table 2. Kaplan-Meier Estimates of Age-Specific Proportions of Women Never Married by Birth Cohort and Years of Schooling $(N=351,742)$

\begin{tabular}{|c|c|c|c|c|c|c|c|c|}
\hline \multirow{2}{*}{ Age } & \multirow{2}{*}{$\begin{array}{l}\text { Years of } \\
\text { Schooling }\end{array}$} & \multicolumn{7}{|c|}{ Birth Cohort } \\
\hline & & 1910-19 & $1920-29$ & $1930-39$ & $1940-49$ & $1950-59$ & 1960-69 & $1970-79$ \\
\hline \multirow{5}{*}{30} & $<12$ & .03 & .02 & .02 & .02 & .04 & .08 & .17 \\
\hline & 12 & .04 & .05 & .05 & .10 & .14 & .18 & .26 \\
\hline & $13-15$ & .07 & .05 & .04 & .14 & .20 & .27 & .43 \\
\hline & $16+$ & .04 & .10 & .09 & .13 & .25 & .38 & .56 \\
\hline & Total & .03 & .03 & .02 & .04 & .09 & .17 & .36 \\
\hline \multirow{5}{*}{40} & $<12$ & .01 & .01 & .01 & .01 & .02 & .05 & --- \\
\hline & 12 & .03 & .02 & .02 & .06 & .08 & .11 & --- \\
\hline & $13-15$ & .00 & .01 & .02 & .08 & .13 & .17 & --- \\
\hline & $16+$ & .04 & .02 & .06 & .10 & .16 & .25 & --- \\
\hline & Total & .01 & .01 & .01 & .02 & .05 & .11 & --- \\
\hline \multirow{5}{*}{50} & $<12$ & .01 & .01 & .01 & .01 & .02 & --- & --- \\
\hline & 12 & .03 & .01 & .02 & .06 & .08 & --- & --- \\
\hline & $13-15$ & .00 & .01 & .02 & .08 & .12 & --- & --- \\
\hline & $16+$ & .04 & .01 & .05 & .09 & .15 & --- & --- \\
\hline & Total & .01 & .01 & .01 & .02 & .05 & --- & --- \\
\hline \multirow{5}{*}{60} & $<12$ & .01 & .01 & .01 & .01 & --- & --- & --- \\
\hline & 12 & .03 & .01 & .02 & .05 & --- & --- & --- \\
\hline & $13-15$ & .00 & .01 & .02 & .08 & --- & --- & --- \\
\hline & $16+$ & .04 & .01 & .05 & .09 & --- & --- & --- \\
\hline & Total & .01 & .01 & .01 & .02 & --- & --- & --- \\
\hline
\end{tabular}

Source: Women's Marriage, Fertility and Employment Surveys: 1979 - 2006. 
Table 3. Cox Model Coefficients (and Standard Errors) for Marriage Rates $(\mathbf{N}=351,742)$

\begin{tabular}{|c|c|c|c|c|c|c|}
\hline Variable & \multicolumn{3}{|c|}{ Model 1} & \multicolumn{3}{|c|}{ Model 2} \\
\hline \multicolumn{7}{|l|}{ Birth cohort } \\
\hline $1910-1929$ & -- & & & -- & & \\
\hline $1930-1949$ & -.14 & $(.01)$ & $* * *$ & -.31 & $(.03)$ & $* * *$ \\
\hline $1950-1969$ & -.37 & $(.01)$ & $* * *$ & -.60 & $(.03)$ & $* * *$ \\
\hline $1970-1979$ & -.74 & $(.01)$ & $* * *$ & -.78 & $(.03)$ & $* * *$ \\
\hline \multicolumn{7}{|l|}{ Years of schooling } \\
\hline Fewer than 12 years & .73 & $(.01)$ & $* * *$ & .52 & $(.03)$ & $* * *$ \\
\hline 12 years & -- & & & -- & & \\
\hline $13-15$ years & -.39 & $(.01)$ & $* * *$ & -.16 & $(.06)$ & $* *$ \\
\hline 16 or more years & -.67 & $(.01)$ & $* * *$ & -.36 & $(.06)$ & $* * *$ \\
\hline \multicolumn{7}{|l|}{ Interaction term } \\
\hline Fewer than 12 years x $1930-1949$ & & & & .17 & $(.03)$ & $* * *$ \\
\hline $13-15$ years x $1930-1949$ & & & & -.02 & $(.06)$ & \\
\hline 16 or more years x 1930-1949 & & & & .01 & $(.06)$ & \\
\hline Fewer than 12 years x $1950-1969$ & & & & .27 & $(.03)$ & $* * *$ \\
\hline $13-15$ years x 1950-1969 & & & & -.23 & $(.06)$ & $* * *$ \\
\hline 16 or more years x $1950-1969$ & & & & -.27 & $(.06)$ & $* * *$ \\
\hline Fewer than 12 years $x 1970-1979$ & & & & .09 & $(.05)$ & $*$ \\
\hline $13-15$ years x $1970-1979$ & & & & -.53 & $(.07)$ & $* * *$ \\
\hline 16 or more years x 1970-1979 & & & & -.85 & $(.07)$ & $* * *$ \\
\hline Log likelihood & $-2,9$ & 53,120 & & $-2,9$ & 52,672 & \\
\hline BIC & & 06,317 & & 5,9 & 05,534 & \\
\hline
\end{tabular}

Source: Women's Marriage, Fertility and Employment Surveys: 1979 - 2006. 


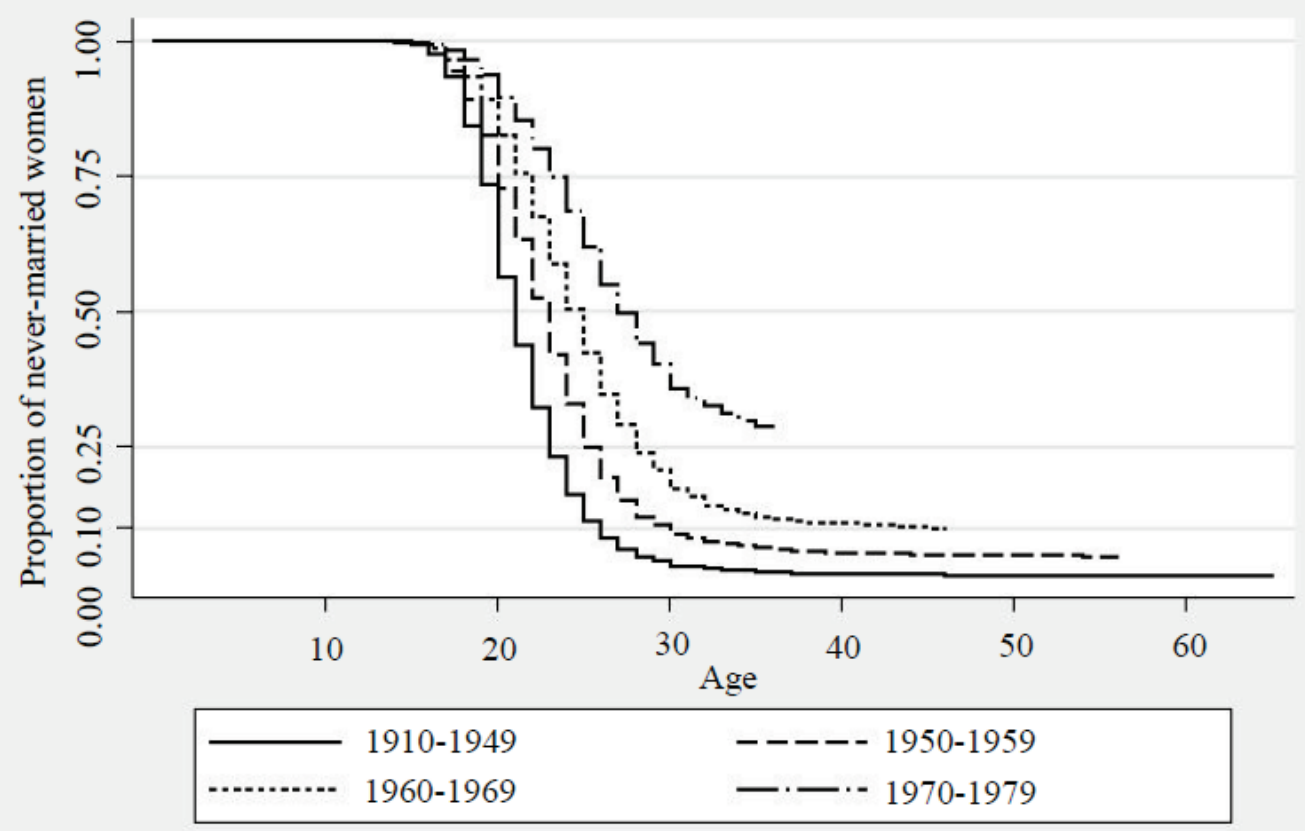

Figure 1. Kaplan-Meier Estimates of Proportions of Never Married Women in Taiwan by Birth Cohort 


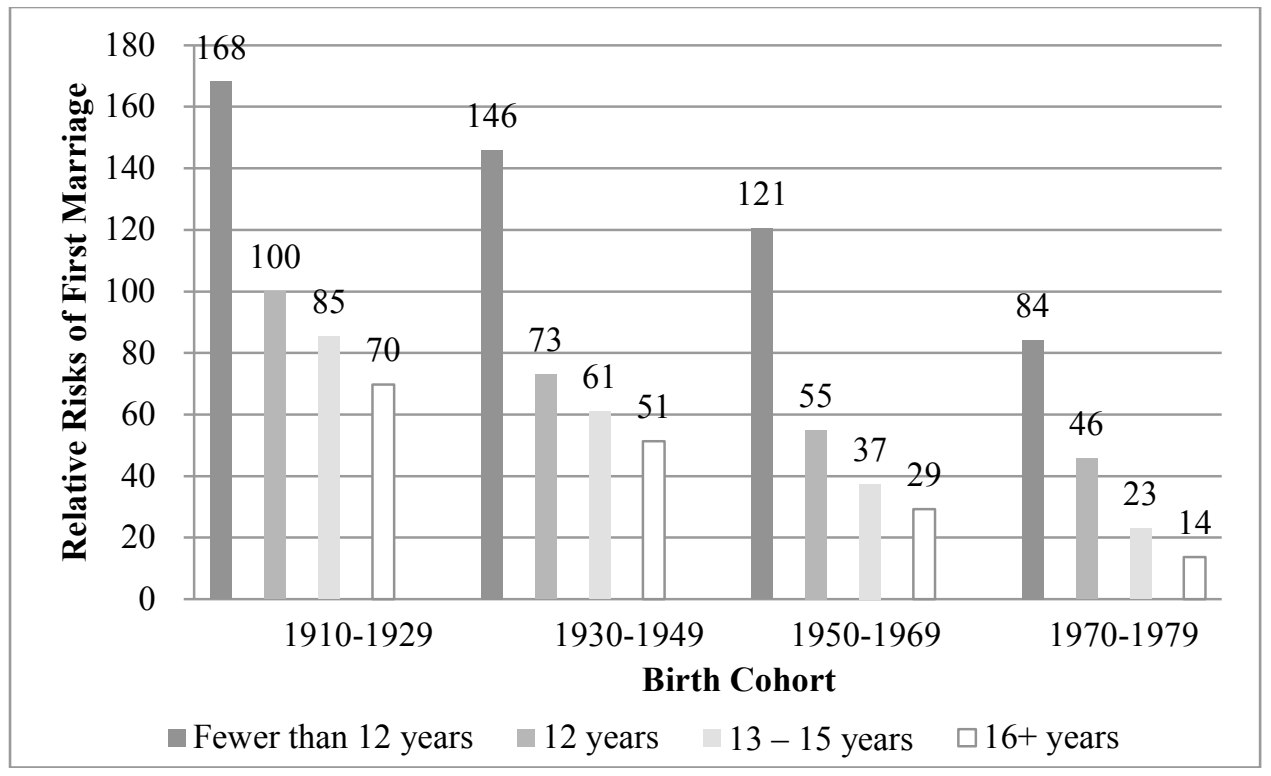

Figure 2. Relative Risks of First Marriage (from Model 2 in Table 3) by Birth Cohort and Years of Schooling 